\title{
Correction to: Activation of SIRT1 by L-serine increases fatty acid oxidation and reverses insulin resistance in $\mathrm{C2C12}$ myotubes
}

\author{
Woo-Cheol Sim • Dong Gwang Kim • Wonseok Lee • \\ Hyungtai Sim • You-Jin Choi • Byung-Hoon Lee
}

Published online: 20 May 2019

(C) Springer Nature B.V. 2019

\section{Correction to: Cell Biol Toxicol \\ https://doi.org/10.1007/s10565-019-09463-x}

The original version of this article unfortunately contained a mistake in the article title.

The article title should have been 'Activation of SIRT1 by L-serine increases fatty acid oxidation and reverses insulin resistance in $\mathrm{C} 2 \mathrm{C} 12$ myotubes' instead of 'Activation of SIRT1 by L-serine increases fatty acid oxidation and reverses insulin resistance in $\mathrm{C} 2 \mathrm{C} 12$ myotubes (L-serine activates SIRT1 in $\mathrm{C} 2 \mathrm{C} 12$ myotubes)'. The corrected article title is shown above.

Publisher's note Springer Nature remains neutral with regard to jurisdictional claims in published maps and institutional affiliations.

The online version of the original article can be found at https://doi.org/10.1007/s10565-019-09463-x

W.-C. Sim • D. G. Kim • W. Lee · H. Sim • Y.-J. Choi • B.-H. Lee $(\square)$

College of Pharmacy and Research Institute of Pharmaceutical Sciences, Seoul National University, Seoul, Republic of Korea e-mail: lee@snu.ac.kr 